\title{
Study of the Training Types of Current Master Candidates in Russia
}

\author{
Shan XU \& Hua JIANG* \\ Harbin Institute of Technology, Harbin, P.R. China
}

\begin{abstract}
As a strong power of education, Russia enjoys a decisive position in the world with the complexity and specificity in its education system. Based on the Russian higher vocational education standards, this paper thoroughly introduces and analyzes the two training types - experts and masters, from three aspects: structural elements, specialty catalogue and teaching program, and then brings up some lessons to the training of master candidates in China.
\end{abstract}

KEYWORD: Structural Elements; Specialty Catalogue; Teaching Program

\section{STUDY BACKGROUND}

Russia boasts the advanced education with a long history, unique features and powerful strength. It owns a group of top-notch scientists and scholars and is evidently dominant in the fields of physics, electronic information and aerospace. The talents training in Russia is classified into two categories: training of bachelors and masters, and training of experts. Experts are equivalent to masters, bearing resemblances with the master candidates in China, European and American countries. In the area of classified training of master candidates and the promotion of the modernization and Internationality of Russian advanced education, its efforts not only generate tremendous domestic impact, but also reveal some lessons that China is expected to learn from. Based on the Russian higher vocational education standards, this paper studies the classified training of master candidates in Russian advanced education by issues analyzing and experiences summarizing from three aspects: structural elements, specialty catalogue and teaching program, and then brings up some lessons and evidences to the reformative practice of the classified training of master candidates in China.

\section{RELATED CONCEPTS}

Since the Russian advanced education is all long different from that of other countries, the writer defines some concepts related in this paper to avoid misunderstandings, including the training mode of master candidates, Russian higher vocational education standards and teaching program.

\subsection{Training mode of master candidates}

The training mode of master candidates refers to the operating method formulated by the training institutions to train the knowledge, skills and qualities of master candidates, based on the regular patterns of high-level talents growth and concerning the specific needs of the society. It mainly contains the training goal, recruitment, schooling system, curriculum, scientific research, instructor's guidance and assessment. [1]

\subsection{Russian higher vocational education standard}

The Russian advanced education is usually called Russian higher vocational education because the training process lays much emphasis on students' practice skills and competency. In order to guarantee the unification of the education space of the Russian Federation as well as the coherence of the different layers of education, Russia has formulated series of education standards against different periods and the social needs of different eras.

According to the No.309 Federation Act on Dec.1st in 2007, the contemporary Russian higher vocational education system mainly contains the requirements of the structure, conditions to realize and the mastery of the basic education outline. 


\subsection{Teaching Program}

In China, teaching program means curriculum standards, while in Russia, the parlance of "teaching program" is initiated by the educational thought of Russian teaching theory, and "curriculum standards" is initiated by the educational thought of BritainAmerican curriculum theory. Since 1990 in Chinese Mainland, "teaching program" is changed into "curriculum program and curriculum scheme". As this paper studies the Russian education, it still uses "teaching program". [2]

The teaching program, issued by the national education departments, means the directive or instructive teaching documents concerning the training process of each major, and it is implemented by the inferior educational departments and schools. A complete teaching program mainly covers the main disciples, curriculum setting, teaching arrangement, schedule, performance evaluation and degree awarding etc. It is lawful, policy-related, reformative, schemed, normative and textual. And it is different from the teaching outline, which means the directive documents of each course in the teaching program. [3]

\section{STANDARDS AND ANALYSIS OF THE RUSSIAN HIGHER VOCATIONAL EDUCATION}

In the year of 1992, the Russian higher vocational education was enacted and carried out by the Russian Federation Education Law. Till now, Russia has issued three generations of higher vocational education standards. In the following paragraphs, the paper will study the training of Russian master candidates from structural elements, specialty catalogue evolution and teaching program.

\subsection{Structural elements}

In the year of 1994, Russia formulated and implemented the first higher vocational education standards, which mainly includes the training orientation or discipline features, the requirement for the training level for individuals and the lowest requirements for the educational outline.

In 2000, Russia formulated and implemented the second higher vocational education standards, which mainly includes the training orientation or discipline features, the lowest requirements for the educational outline and some general requirements for the training level of middle students, the time limit to accomplish the educational outline, the conditions to realize the educational outline and training level for students in professional fields. Based on the second generation of standards, Russian Association of Teaching Method also formulated the model teaching program of each major.
From 2006 to 2010, Russian National Department of Educational Policy and Standard Law Coordination set up specialized work group to draw up the third generation of standards on the basis of the experiences and accomplishments of the advanced education. The structural elements of the third higher vocational standards add up to 8 items: training orientation or discipline features, the demand for the conditions to formulate and realize the basic educational outline, range of application, the use of abbreviation, the features of professional practice, the demand for the mastery of the basic educational outline, the demand for the structure of the basic educational outline and the assessment of the quality of the basic educational outline.

To sum up, the first edition of standard is in the period of exploration with the focus on the general demand for the curriculum content and volume. Compared with the first one, the second generation of standard is added with many items but it still inherits the focus of the first. Distinctively, the third higher vocational education standard transferred the emphasis to the demand for the mastery of the basic educational outline. It is evident that the goal of the Russian higher vocational education is gradually gaining its clarity and closely combines the course and competency, with more focus on the training of students' abilities.

\subsection{Specialty Catalogue}

There are two parallel systems of Russian advanced education: the system of "bachelor-master-vice doctor-doctor" and the system of "expert-vice doctor-doctor". That is to say, the status of experts equals to that of master candidates. In addition, in the first generation of Russian higher vocational education, experts are trained according to the majors, while the bachelors and master candidates are trained based on the disciplines. In the second version of standard, the experts are trained in both ways of majors and disciplines, while the training of bachelors and master candidates remains the same. In the third generation, bachelors, master candidates and experts are all trained in a broader sense. It should be noted that before the implementation of the third Russian higher vocational education standards, "experts" are usually called "diploma experts".

It can be concluded from the two tables that in the first generation of education standards, the number of fields and majors of the experts training is much more than those of bachelors and masters. The overdivided majors cultivate the experts who can only get employed in a certain professional field. In the second generation of education standards, some adjustments have been made to the training of diploma experts who are trained in a broader sense, but the training system of bachelors and masters are 
still not populated. In the third generation of education standards, the experts training is kept while its field and number of majors have changed a lot compared to the first generation. Besides, the fields and the number of majors of the bachelors and masters training have also increased a lot, exceeding the counterparts of experts training.

Table 1. Specialty Catalogue of Experts Training(Orientation Catalogue).

\begin{tabular}{|l|l|l|}
\hline Experts training & $\begin{array}{l}\text { Specialty Catalogue } \\
\text { (Fields/Specialty) }\end{array}$ & $\begin{array}{l}\text { Orientation } \\
\text { Catalogue }\end{array}$ \\
\hline 1st generation & $32 / 420$ & none \\
\hline 2nd generation & $10 / 170$ & $4 / 84$ \\
\hline 3rd generation & none & $25 / 107$ \\
\hline
\end{tabular}

Table 2. Orientation Catalogue of Bachelors and Master Training.

\begin{tabular}{|l|l|}
\hline Bachelors and masters Training* & $\begin{array}{l}\text { Orientation Catalogue } \\
\text { (Field/Orientation) }\end{array}$ \\
\hline 1st generation & $5 / 89$ \\
\hline 2nd generation & $5 / 95$ \\
\hline 3rd generation & $\begin{array}{l}27 / 171 \text { (Bachelor) } \\
27 / 175 \text { (Master) }\end{array}$ \\
\hline
\end{tabular}

*The Orientation Catalogue of the first two generations is identical. In the third generation, bachelor and master training share 27 same majors while differ in the specific major in the educational area.

This is closely related to the fact that Russia takes an active role in the internationality of advanced education and that it joins the Bologna Process. The globalization of political economics brings the internationality of education. In order to comply with the trend and attract more international students to ease the tight education budget, Filippov, the minister of Russian Federation Department of Education signed the Bulletin of Establish Unite European Advanced Education Space on the conference of advanced education ministers among the "Bologna Reform" members in Berlin, on Sep.18th-19th in 2003. It means that Russia is expected to realize the basic education target and principle formulated in the Bologna Declaration. To specify, the bachelor-master degree system of advanced education is one of the core reform proposed in the Bologna Declaration.

\subsection{Teaching Program}

This paper selects the current teaching program of Bauman Moscow State Technical University (BMSTU) to start the analysis for the sake of specification. BMSTU, the oldest and largest technical university in Russia, was founded in 1830. It cultivates large numbers of wonderful technical talents for form Soviet Union and Russia, sharing the similar status of Tsinghua University in China. However, it should still be pointed out that since scarce majors in BMSTU offer the training of bachelors, experts and masters at the same time, the writer selects the major of "Aircraft Control System" to analyze the experts teaching program, and the major of "Project Management" to analyze the bachelors and masters teaching program, with the focus on the formation and proportion of the specialized courses.

The expert courses of the major "Aircraft Control System" in BMSTU mainly contain human and social economics (13\%), mathematics and natural sciences $(26 \%)$, professional courses $(46 \%)$, practice of production $(7 \%)$ and national graduation appraisal (7\%). The total duration is 5169 hours with 360 credits.

The bachelor courses of the major "Project Management" in BMSTU mainly contain human and social economics (16\%), mathematics and natural sciences (34\%), professional courses (39\%), practice of production $(5 \%)$ and national graduation appraisal (5\%). The total duration is 4208 hours with 240 credits. The master courses contain general science courses $(22 \%)$, professional courses $(40 \%)$, practice of scientific research $(26 \%)$ and national graduation appraisal (12\%). The total duration is 888 hours with 120 credits. [4]

Concluded from the formation of course system or the proportion of each item, it is evident that Russia lays more and more emphasis on the general quality of students, but different types of talents are trained with different focuses. Professional courses occupy nearly a half of the expert course system, indicating that the experts training in BMSTU still pay much attention to the specialty of students. In its master courses, professional courses still take up a large share, but it is attributed to the nature of technical university itself. What's important is that the practice of scientific research is added. Besides, the national graduation appraisal, or the graduation thesis occupy $12 \%$ in the master course system, with a 5\% increase compared to that of experts training, which reveals that the master training in Russia values more of students' academic abilities.

In addition, in terms of total academic hours and credits, the bachelors are much less than experts. Thus, graduates with bachelor degrees are much more inferior to those with expert degree when they seek for employment.

\section{EVALUATION AND LESSONS OF TRAINING TYPES OF CURRENT MASTER CANDIDATES IN RUSSIA}

It is observed that majorities of Russian master disciplines adopt the path of "bachelor plus master", while a few disciplines still train experts. On the one hand, it accords with the trend of the internationality of advanced education and symbolizes a big step 
from the Bologna Process. The diploma and qualifications from Russian advanced education gains recognition from the European markets, broadening the employment space of Russian college students and facilitating the flowing of teachers, students and research faculties. On the other hand, Russian advanced education is still unsure about the training of talents. Russia has made a successful transformation in the training types, but it still keeps the trails of the old training mode. Take BMSTU as an example, the professional courses are still dominant in the master course system. Besides, the status quo of Russian current training types of master candidates leads to the lower quality and the outflow of talents in the Russian advanced education to some extent.

The links between Chinese and Russian boast a long history and it is of great value to study the experiences of the educational reform of Russian master candidates. As the progress of the human knowledge system and education system, the internationality of advanced education will become an irreversible trend with increasingly frequent interactions between countries. We China should learn from the principles and strategies of Russia in its educational communication and cooperation. We should actively take part in the competition of international education market and revolutionize the educational system on the basis of the favor of national sovereignty and interests. At the same time, we should also learn from the lessons of Russian educational reform. Faced with the advancement of social economics and science and technology, as well as the change for the talents need, the writer suggests that students should be trained in two types: academic and specialized. Thus, we can identify the training goal of different types of master candidates, formulate the feasible training scheme and highlight the training features of different types of master candidates.

\section{REFERENCES}

[1] J.L, Zheng. Study of classified cultivation of graduate students In the higher education popularity stage. Modern Education Management: 2011(2): 111-113.

[2] L.L, Yang \& L.Z, Pan. Research on element of curriculum standards. Education Journal: 2010(2):38-47.

[3] R.Q, Wu. The effect of teaching program, syllabus and teaching material in teaching. Journal of Hainan Medical College: 2005(11):354.

[4] http://hoster.bmstu.ru/ mo/plan.html 